Article

\title{
Climate Change Adaptation and Vulnerability Assessment of Water Resources Systems in Developing Countries: A Generalized Framework and a Feasibility Study in Bangladesh
}

\author{
Animesh K. Gain ${ }^{1{ }^{*} \text {, }}$ Carlo Giupponi ${ }^{1}$ and Fabrice G. Renaud ${ }^{2}$ \\ 1 Department of Economics, Ca' Foscari University of Venice, Cannaregio 873, Venice 30121, Italy; \\ E-Mail: cgiupponi@unive.it \\ 2 Institute for Environment and Human Security (UNU-EHS), United Nations University, \\ Herman-Ehlers-Strasse 10, Bonn 53113, Germany; E-Mail: renaud@ehs.unu.edu \\ * Author to whom correspondence should be addressed; E-Mail: animesh.gain@gmail.com; \\ Tel.: +39-041-234-9109; Fax: +39-041-234-9176.
}

Received: 15 February 2012; in revised form: 12 March 2012 / Accepted: 29 March 2012 /

Published: 10 April 2012

\begin{abstract}
Water is the primary medium through which climate change influences the Earth's ecosystems and therefore people's livelihoods and wellbeing. Besides climatic change, current demographic trends, economic development and related land use changes have direct impact on increasing demand for freshwater resources. Taken together, the net effect of these supply and demand changes is affecting the vulnerability of water resources. The concept of 'vulnerability' is not straightforward as there is no universally accepted approach for assessing vulnerability. In this study, we review the evolution of approaches to vulnerability assessment related to water resources. From the current practices, we identify research gaps, and approaches to overcome these gaps a generalized assessment framework is developed. A feasibility study is then presented in the context of the Lower Brahmaputra River Basin (LBRB). The results of the feasibility study identify the current main constraints (e.g., lack of institutional coordination) and opportunities (e.g., adaptation) of LBRB. The results of this study can be helpful for innovative research and management initiatives and the described framework can be widely used as a guideline for the vulnerability assessment of water resources systems, particularly in developing countries.
\end{abstract}

Keywords: vulnerability; water resources; climate change; decision-making; adaptation; lower Brahmaputra river basin 


\section{Introduction}

Freshwater systems are part of larger ecosystems which sustain life and all social and economic processes. The provision of freshwater is therefore an ecosystem service which, when disrupted, threatens both the health of ecological systems and human wellbeing, which are in complex interaction [1]. Through the primary medium of water, climate change influences the Earth's ecosystems, people's livelihoods, and general human wellbeing [2]. Scientists within the Intergovernmental Panel on Climate Change (IPCC) expect that the present increase in greenhouse gas concentrations will have direct first-order effects on the global hydrological cycle, with impacts on water availability and demand [3]. These changes will in turn create other higher order effects [4], which are shown in Figure 1. Overall at the global level, a net negative impact on water availability and on the health of freshwater ecosystems is foreseen [5], and thus a cascade of negative consequences is expected to affect social and ecological systems and their processes.

Figure 1. Different order climate change effects on water resources.

\section{First Order}

Increase in ambient air temperature; changes in evaporation, precipitation, streamflow; sea level rise

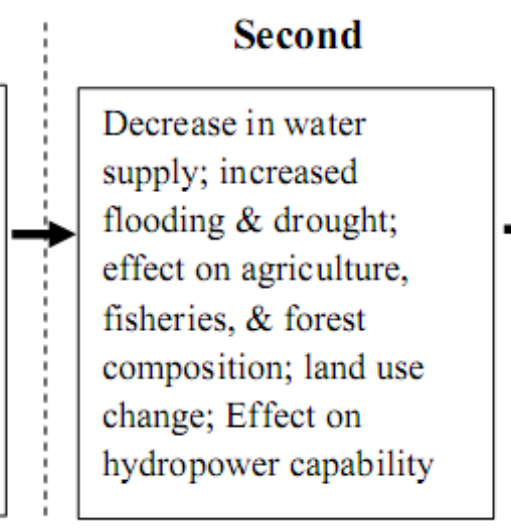

Third Order

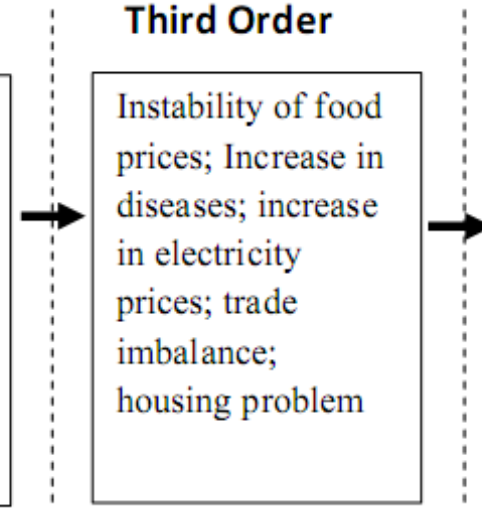

Fourth

Migration, unemployment, economic development, national security

Besides climate, there are other drivers of change, such as increased population pressure, economic development and urbanization trends. These drivers of change are closely linked to each other and pose complex management problems for land and water resources. As populations grow and move to cities - and as their income levels increase or decrease - their demand for water resources changes both spatially and temporally. Taken together, the net effects of these supply and demand changes in areas of increasing population, can translate into increases in the vulnerability of water resources systems, which can create major challenges for future management of water resources for human and ecosystem needs. As stated above, climate change can contribute further to exacerbate problems, in particular when considering medium to long term projected impacts. There is therefore a need to assess the vulnerability of water resources systems for enhanced management strategies, also including robust adaptation measures for future sustainable water use.

Vulnerability assessment is not straightforward, in particular because there is no universally accepted concept for vulnerability. For example, Thywissen [6] lists 35 definitions of the term. The plurality of the definitions leads, as expected, to very diverse assessment frameworks and methods [7-13]. Some authors even argue that by principle, vulnerability cannot be measured as it does not denote observable phenomena [14,15] while, according to [16] the opportunity arises to make this theoretical concept operational. Indicators can provide the means for doing so and, in particular, make the 
assessment of vulnerability possible, as we propose herein with the methodological framework for the assessment of the vulnerability of water resources, within the broader context of climate change adaptation, and with a specific emphasis on operational implementation in developing countries.

Water resources systems are complex in nature and consist of four inter-linked sub-systems: individuals, organizations, society and environment [17]. As a consequence, management issues should generally consider multiple decisional criteria and large numbers of possible alternatives, usually characterized by high uncertainty, complex interactions, and conflicting interests of multiple stakeholders, but also of a multiplicity of compartments, such as river, land or coastal ecosystems, or different economic sectors [18]. Due to this dual complexity (i.e., complexity in vulnerability assessment itself and complexity of water resources management), not many studies of vulnerability assessment of water resources systems are available to date. The issue of vulnerability was first brought to the attention of policy makers in an international context in the field of water resources management in 1992 at the Dublin Conference [19] (Dublin Principle 1 states that fresh water is a finite and vulnerable resource, essential to sustain life, development and the environment). Later, several studies on the vulnerability assessment of water resources systems were carried out at various geographical scales, e.g., global scale [20], large scale trans-boundary river basin [21,22], regional scale [23,24] and also in small scale watersheds [25-28]. A few studies e.g., Balica et al. [29] also include the variation of vulnerability value across different spatial scales, ranging from river basins to urban areas. In some of these studies [20,23,26], vulnerability is considered only as a physical component of water resources and these studies focus on water resources availability rather than how society and the ecosystem deal with water [28]. Global and large scale studies usually cannot provide the detailed information that is required for appropriate adaptation and management actions [27]. Other studies [22,25,27,28] incorporate important components (i.e., exposure, sensitivity, adaptive capacity) of vulnerability in their assessment, but limited stakeholders' involvement can produce subjective biases and limited credibility. Typically a dichotomy exists between engineering science approaches and those focused on the human dimension, with the first commonly lacking adequate consideration of stakeholders' involvement as required by the most relevant international references in the field, such as the Dublin Principles [19] (Dublin Principle 2 states that water development and management should be based on a participatory approach, involving users, planners and policy makers at all levels.). Similarly, a society cannot improve without the support of innovative scientific ideas and technical knowledge.

Given the above, the specific objective of this study is to propose a generalized framework for scientifically based vulnerability assessment to support participatory decision making processes in the field of water resources management (WRM), with a specific interest for climate change adaptation (CCA). In developing such a framework, the following section reviews the most recent international literature, while the framework itself is described in Section 3. Section 4 introduces the Lower Brahmaputra River Basin (LBRB), the case study utilized for preliminary feasibility analysis of the proposed approach with its potential implementation on the LBRB area and discusses the results of a survey with local experts and stakeholders. Finally, Section 5 concludes the results discussing the operationalization of the framework and the experiences in the study case and identifies future research needs. 


\section{Vulnerability Assessment Models and Frameworks}

\subsection{Framing the Concept of Vulnerability}

The scientific use of the term 'vulnerability' has its roots in geography and natural hazards research but this term is now a central concept in a variety of other research contexts such as ecology, public health, poverty and development, livelihood and food security, sustainability science, land use change, and climate change impacts and adaptation. Each disciplinary field defines 'vulnerability' in different ways. Birkman [30] provides an overview of the evolution of the different spheres of widening vulnerability concepts evolving from intrinsic risk factors to a much broader multidimensional concept, encompassing physical, social, economic, environmental and institutional features. Within such broader vision, different schools of thought have developed and some of them are of specific interest here: (i) the climate change adaptation (CCA) community [12,13,31,32]; (ii) the disaster risk reduction (DRR) community [33-35]; and (iii) the global environmental change (GEC) and sustainability science community [10,36]. The assessment of vulnerability is intrinsically linked to the notion of these different schools of thought. Each of these conceptual approaches can lead to the formulation of diverse policies. As a consequence, Eakin et al. [37] suggest that the trade-off between alternative approaches should always be made explicit.

The DRR school of thought was established in 1970s and views disasters as having socio-economic and political origins [38,39]. Later, it considered the wider social, political, environmental and economic dimensions of hazards [40]. The strategies for DRR include hazard, vulnerability and coping capacity assessments, as well as understanding the community's ability to reduce its own risks [33]. More recently, CCA policy negotiations have started considering ways to reduce vulnerability to the expected impacts of climate change. Although the DRR and CCA communities have both been engaged in reducing socio-economic vulnerability to natural hazards, they have given different definitions and conceptualizations of the same terminology [40-42]. For example, the conceptualization of vulnerability by the DRR community [43] is different from the conceptualization by the CCA community [44]. The International Strategy for Disaster Reduction (UN/ISDR) defines vulnerability as the conditions determined by physical, social, economic and environmental factors or processes, which increase the susceptibility of a community to the impact of hazards [43], whereas the IPCC defined 'vulnerability' as "the degree to which a system is susceptible to, or unable to cope with, adverse effects of climate change, including climate variability and extremes. Vulnerability is a function of the character, magnitude, and rate of climate variation to which a system is exposed, its sensitivity, and its adaptive capacity" [45]. Hinkel [16] criticizes the definition of the IPCC as being too vague and the resulting difficulty in making it operational. However, the definition provided by the IPCC is one of the most generic available, and thus it could be considered as a basis for further refinement, such as was the case of the global environmental change and sustainability science communities, who introduced the notion of the coupled social-ecological system (SES), also referred to as human-environment system, in conceptualizing vulnerability [10]. We follow the IPCC definition of vulnerability for the purpose of this research.

Notwithstanding the terminology problems, there is an evident and urgent need for vulnerability assessment of coupled systems for adaptation to the foreseeable consequences of climate change [42]. In 
climate change adaptation, vulnerability assessment for the future is considered as the forward-looking aspects of vulnerability. Hinkel [16] states that forward looking aspects are one of the most important characteristics of vulnerability and their incorporation in the assessment is one of the most challenging tasks. Indeed a forward-looking approach should be considered as a prerequisite for any study targeting adaptation to climate change. According to [13], for climate change vulnerability assessment, more specifications are required and at least four fundamental dimensions should be incorporated in the assessment, i.e., the system, the attribute(s) of concern, the specific hazard and the temporal reference. The system of analysis is typically a coupled social-ecological system, a population group, an economic sector, a geographical region, or a natural system, and the examples of attributes of concern may include human lives and health, the existence, income and cultural identity of a community, or the biodiversity, carbon sequestration potential and timber productivity of a forest ecosystem. Hazards can be related to climatic variables, such as extreme rainfall events and the consequent flood risk. The temporal reference when dealing with the CCA typically considers a rather wide future time frame, long enough to appreciate the effects or expected changes of climatic variables. According to these four dimensions, the assessment context for our research could thus be defined as: "vulnerability of water resources systems to climate change at the river basin or sub-basin scale, over the next 50 years".

\subsection{System View in Water Resources Management and Decision Making}

Considering water resources systems (WRS), individuals, organizations and society can be considered as a social system which is nested within an ecological system [17]. Therefore, it is the complex interactions of the social-ecological system that make decision making more and more difficult in the WRS and the traditional fragmented approach of water management has to be replaced by more holistic system view approaches [46]. Integrated Water Resources Management (IWRM) is such an approach that has been widely accepted internationally as the way forward for efficient and equitable management of water resources.

The Global Water Partnership defined "IWRM as a process, which promotes the coordinated development and management of water, land and related resources, in order to maximize the resultant economic and social welfare in an equitable manner without compromising the sustainability of vital ecosystem" [47]. Within the concept of IWRM, the United Nations World Water Development Report 3 describes the decision-making process of water resources in more comprehensive way [48]. According to this approach, water managers inform the initial steps of the decision-making process and participate in planning the appropriate responses, interacting with the principal actors (policy makers) and with the managers of other sectors. Water managers address the demands of water users to meet the life-sustaining requirements of people (social dimension) and the needs of other species (ecological dimension) and to create and support livelihoods, by implementing an iterative and adaptive participatory process. Although IWRM is considered by a majority of scientists and experts as useful theoretical framework, it is now openly debated whether it is truly effective in terms of operational implementation. The IWRM approach can nevertheless provide an opportunity for the development of a method for vulnerability assessment, which thus becomes one of the main components of the process to manage water resources with a holistic approach targeting the whole WRS. 


\subsection{Indices for the Assessment of Vulnerability of Water Resources}

With the aim of providing quantitative assessment of vulnerability, several indices have been proposed in the field of water resources. Very often, vulnerability assessment of water resources incorporates only physical components consisting, for example, of water scarcity calculations using the water scarcity index which can be defined as the ratio of water demanded to the supplied volumes. Following this index, a number of studies have been carried out at the global scale [20,49-53]. However, annual level assessment of water scarcity does not incorporate the fact of inter-annual seasonality. For example, large parts of monsoon Asia suffer from severe water scarcity in dry periods while the average annual resource availability appears to be plentiful. In addition to this, as stated above, the water scarcity calculation considers water only as a 'physical resource', rather than as one component of a much broader and more complex WRS.

With a more holistic system view of water resources, several recent studies [21,22,25,27,29] have conducted vulnerability assessment and proposed other concise indices. Pandey et al. [25] attempted to provide an operational definition of vulnerability as the ratio of water stress index (WSI) to adaptive capacity index (ACI) and compare the results among three sub-watersheds (i.e., Manamatta, Palung and Range) of the Bagmati River Basin. In this assessment, WSI was calculated from the aggregation of four water stress parameters (e.g., water variation, water scarcity, water resource exploitation and water pollution) and ACI was calculated from the aggregation of the parameters of natural capacity, physical capacity, human resource capacity, and economic capacity. Considering social, economic, environmental and physical components, Balica et al. [29] constructed a flood vulnerability index (FVI) that was applied to compare vulnerability among three different spatial scales: river basin, sub-catchment and urban areas. In several other studies [21,27,54], 'vulnerability of a river basin' is expressed as a function of resources stress (RS), development pressure (DP), ecological security (ES) and management challenges (MC). RS, DP, ES and MC are considered as components of vulnerability and each component has several parameters. In the assessment, aggregation of the parameters between water stress and water variation, water exploitation and safe drinking water inaccessibility, water pollution and ecosystem deterioration, water use efficiency, improved sanitation accessibility and conflict management capacity represents RS, DP, ES and MC respectively. The vulnerability index $(V I)$ is calculated by aggregating four vulnerability components with equal weights given to the parameters, as shown in Equation (1).

$$
\mathrm{VI}=\sum_{i=1}^{n}\left[\left(\sum_{j=1}^{\mathrm{m}_{i}} x_{i j} \times w_{i j}\right) \times W_{i j}\right]
$$

where $V I$ is vulnerability index; $n$ is the number of vulnerability components; $m_{i}$ is the number of parameters in the $i$ th component; $x_{i j}$ is the $j$ th parameter in the $i$ th component; $w_{i j}$ is the weight to the $j$ th parameter in the $i$ th component; and $W_{i}$ is the weight given to the $i$ th component.

The indicators and the variables that are considered in these studies were not selected with the involvement of local stakeholders. However, it is necessary to investigate local perceptions in order to identify appropriate indicators that can play an important role for effective decision making. Very recently, Sullivan [24] developed a water vulnerability index (WVI), in which indicators were identified by local stakeholders in municipalities in the South African portion of Orange River Basin. The WVI is calculated based on two major dimensions: vulnerability of water systems which is 
considered as supply-driven vulnerability and vulnerability of water users which is termed as demand-driven vulnerability.

From the above review, we can summarize some conceptual gaps. Firstly, the lack of consideration of forward-looking aspects (or future aspects) is one of the main shortcomings of vulnerability assessment in general, and vulnerability assessment of water resources systems in particular. Secondly, instead of annual level assessment of water scarcity, seasonal variations reflecting water abundance and scarcity regimes should be considered. Thirdly, for vulnerability assessment of water resources systems, it is necessary to move from static (usually cartographic) indexes (i.e., physical water scarcity index) to more complex assessments based upon the concept of social-ecological system. Fourthly, vulnerability assessment should be accomplished through involving stakeholders.

\section{Proposed Framework of Vulnerability Assessment for Water Resources System}

In order to overcome the conceptual gaps identified in Section 2, we propose and describe a logical sequence of steps for vulnerability assessment of water resources systems which is shown in Figure 2. In the following description, each step of Figure 2 is represented by letter, a-n. For example, step 1 (identify key stakeholders) is shown as Figure 2a.

Figure 2. Steps of the proposed framework for vulnerability assessment of water resources system.

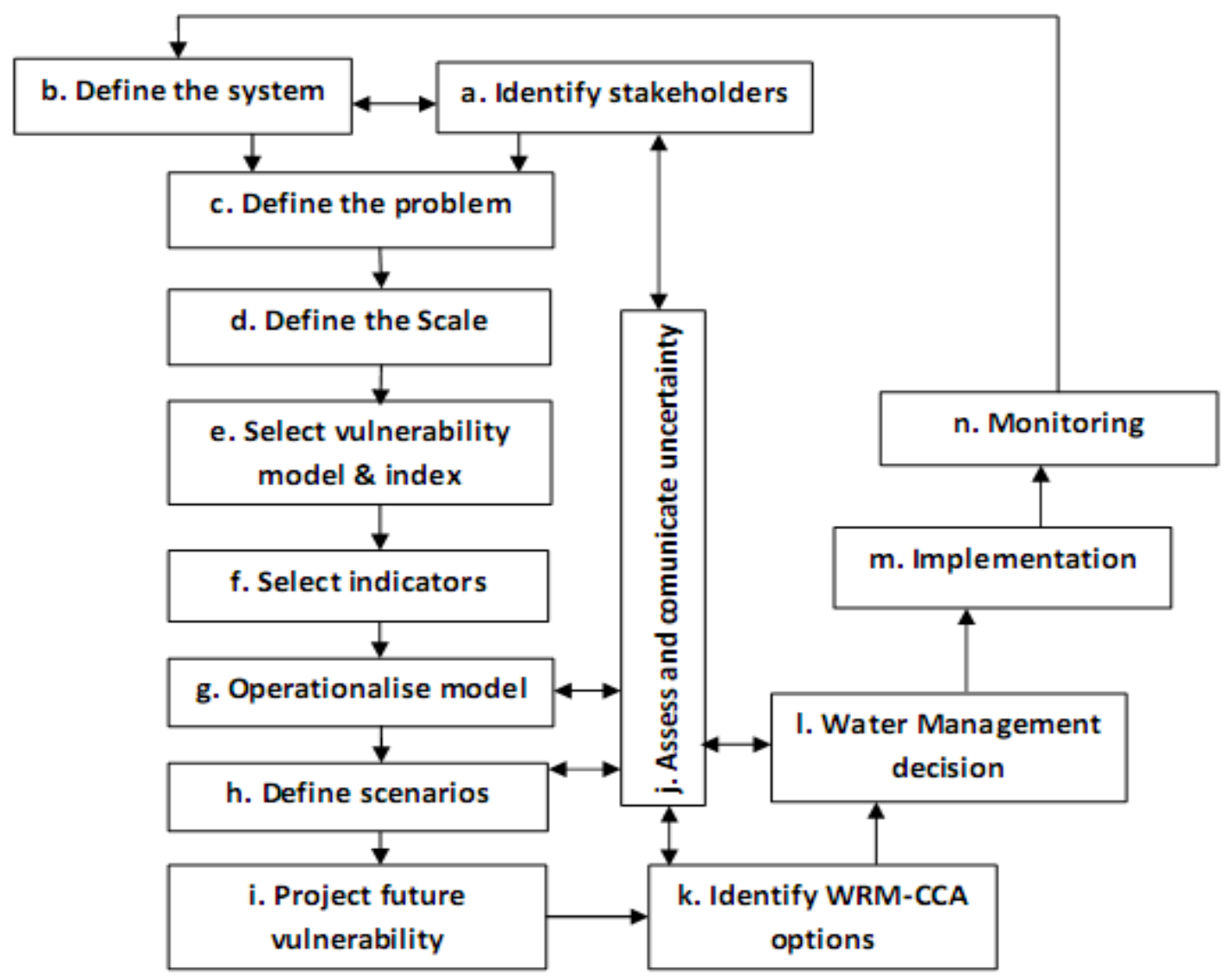

In the framework, the first - iterative - step of the assessment is to identify stakeholders and with the involvement of them it is required to define the water resources system (Figure 2a,b). Stakeholders 
are individuals or groups whose interests are affected by a system or a decision as well as those whose activities significantly affect the system. To reduce the risks of failing to identify key stakeholders, robust methods are therefore needed. With the involvement of these stakeholders, the water resources system can be defined and the problem is to be explored (Figure 2c) in order to identify most important concerns and conflicts of the system.

Once the system's boundaries are defined, both spatial and temporal scales of the study (Figure 2d) need to be determined with the involvement of stakeholders. To capture the vulnerability of the water resources system, different types of scales have to be considered: a scale representing the physical water resources subsystem, a scale representing the social subsystem, and if necessary, an additional scale that contains temporal and administrative aspect [29]. Figure 3 (adapted from [55,56]) shows the distinct types of scales and respective levels that may be relevant to the water resources system. The bio-physical (water resources) scale ranges from a single watershed to the global hydrologic system. Among the mentioned scales, at least, spatial and temporal units of analysis need to be congruent with the purpose of the assessment. Depending on the purpose of water resources decision making, any of the hydrologic boundaries (watershed, sub-basin, basin, region, etc.) can be considered as the standard level for the spatial scale.

Figure 3. Schematic illustrations of different scales and levels (adapted from [55,56]).

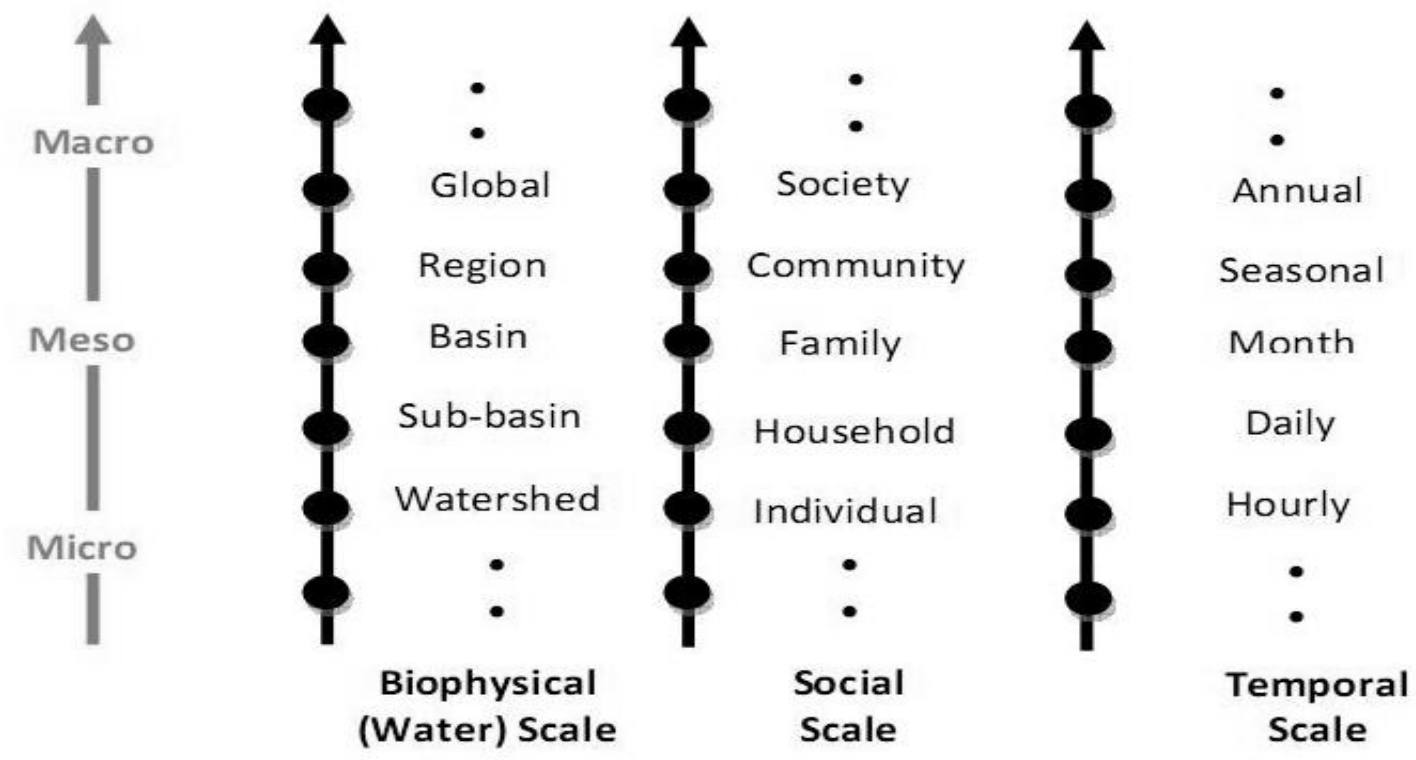

After having defined the system and chosen both spatial and temporal scales, the next step is to select a vulnerability model for the assessment (Figure 2e). To date, a number of vulnerability assessment models have been developed by different research communities as described above. Depending on the purpose of the analysis, we can identify which of the models could better represent the system. The selected models can be later adapted to better account for the dynamics of the system under study.

Once the scale of the assessment is identified and the vulnerability assessment model of the water resources is selected, the next step is to select representative indicators (Figure 2f). Adger et al. [57] identify two general approaches for indicator selection: (i) the deductive approach which is based on a 
theoretical understanding of relationships, and (ii) the inductive approach which is based on statistical relationships among a large number of variables. An inductive approach needs one or more proxy variable for vulnerability as the benchmark against which indicators are tested. However, the paradox is that the need for vulnerability indicators is because there is no such quantifiable element of vulnerability. Therefore, we recommend a deductive approach for indicator selection. In a deductive approach, concepts need to be operationlized in order to test variables empirically: first, to create an understanding of the investigated phenomena and the processes involved; second, to identify the main processes to be included in the study; and, finally, we can move to select the best possible indicators for these factors and processes [57]. Subsequently, different indicator approaches that cope with similar objectives may be reviewed in order to retrieve a list of prominent indicators that might be valid for the specific problem. Then, a pre-selection of potential indicators can take place. These indicators are tested carefully following respective selection criteria, data quality, and statistical correlations. In order to validate representative indicators, involvement of water managers, researchers, other resources managers, policy makers and key stakeholders is essential [56]. Subsequently, the final indicator set can be defined, that comprehensively represents the system identified at the beginning of the procedure. This step is followed by data collection. Vulnerability assessment is an integrated assessment which requires social, economic and physical data. Therefore, sources of these data are diverse. For hydrologic and socio-economic data, secondary sources held by e.g., national statistics offices, relevant government and non-government organizations can be used. At the same time, information derived from public participation and stakeholder focus group discussions can also be used.

Model operationlization (Figure $2 \mathrm{~g}$ ) usually also involves aggregation and possibly weighting for the calculation of a concise index. The analytical hierarchy process (AHP), proposed by Saaty [58], is perhaps the most widely used method for aggregating indicators and evaluating and ranking alternatives within a decision making process, but many other methods exists, in particular within the broadest family of Multi-Criteria Decision Methods. To aggregate indicators, it is necessary to normalize them. There exist a number of different normalization functions for a variety of different indicators. The most common application is to determine desirable and least acceptable (best and worst) values and to normalize the measured value between the two threshold values. The type of normalization function depends on the indicator under consideration and the preferences of the decision maker. Given the often not immediate relationship of indicator values with the objective of the assessment, the application of value function can play an important role. Value functions are mathematical representations of human judgments which offer the possibility of treating people's values and judgments explicitly, logically and systematically [59]. To construct composite indicator value and or index, the weighting of indicators are then to be carried out reflecting stakeholders' views.

Given the uncertainty pervading future projections, and in particular those considering climatic changes, vulnerability assessment for supporting CCA, has to consider multiple scenarios representing plausible future directions of development of the most important variables (and related indicators) in the area of interest (Figure $2 \mathrm{~h}$ ). A scenario is a coherent, internally consistent and plausible description of a possible future state of the world [44]. In the vulnerability assessment of water resources, both climatic as well as socio-economic scenarios for business-as-usual and policy options are important. Climate scenarios are scenarios of climatic conditions, whereas socio-economic scenarios are scenarios of the state and size of the population and economy. For collecting the needed indicator values, outputs 
of simulation models are used. For example, the impact of climate change on water resources is usually estimated by defining scenarios of changes in climate conditions, simulated by general circulation models (GCMs), and linking them to a hydrological model to predict changes in river runoff, groundwater recharge and extraction rates. Similarly, the hydrologic model can be parameterized with data coming from economic models (e.g., general or partial equilibrium models) and providing estimations of the most important variables of the social system, including for example land use. The outputs of the hydrologic model are then used as input of this indicator based approach. Similarly, for other socio-economic indicators, multiple scenarios have the additional advantage that a better understanding of the system under consideration is obtained.

Once the vulnerability is assessed for both the present and for future scenario (Figure 2i), the next step is to identify adaptation options that may reduce the vulnerability (Figure 2k). Uncertainties of the results should be communicated among the stakeholders (Figure 2j). Policy makers, local stakeholders and interdisciplinary researchers are to be involved in identifying appropriate adaptation options. Based on the vulnerability assessment results and identified options, water management decisions are to be taken with the involvement of stakeholders (Figure 21). This process has natural consequences on the implementation of a decision taken. The basis of results obtained and the decision taken is in fact an adaptive management process from which we can identify a series of preferred options that is to be implemented (Figure 2m,n). For improved decision making, the process then starts again in an iterative manner.

\section{Feasibility Assessment of Proposed Framework in Lower Brahmaputra River Basin (LBRB) Context}

The main purpose of the generalized framework is to provide a guideline that can be useful for water resources decision making, facilitating in particular the consideration of a new dimension in water resources management, namely climatic change trends and thus integrating climate change adaptation into operational planning and management practices. Describing a generalized framework, detailed background information representing a system is required. In this case, the context of LBRB is defined for providing and describing the generalized framework. The feasibility study in the part of LBRB (in Bangladesh) was aimed at providing a preliminary test of the framework's potential for practical implementation and important feedback for its refinement and finalization.

\subsection{Lower Brahmaputra River Basin (LBRB): Context of Vulnerability Assessment}

The Brahmaputra is a major transboundary river which has a catchment area of around 530,000 $\mathrm{km}^{2}$ and crosses four different countries (China, India, Bangladesh and Bhutan). Immerzeel [60] categorized the Brahmaputra basin into three different physiographic zones: Tibetan Plateau (TP), Himalayan belt (HB), and the floodplain (FP). The FP area, with an elevation of less than $100 \mathrm{~m}$ above the sea level which comprises about $27 \%$ of the entire Brahmaputra basin comprising parts of Bangladesh and North-East India is called the Lower Brahmaputra River Basin [60,61]. More than 10 million people live in LBRB.

The hydrological impact of climate change on the LBRB is expected to be particularly strong because of two principal reasons. First, the projected rise in temperature will lead to increased glacial 
and snow melt, which could lead to increased summer flows in the river system for a few decades, followed by a reduction in flow as the glaciers disappear and snowfall diminishes [60]. Second, an important characteristic of the basin is the influence of the monsoon climate [62,63], which is characterized by a seasonal change of wind direction, carrying no moisture during the dry season (from September to June), whereas, the winds from the ocean carry a lot of moisture leading to heavy rains during the rest of the year. Beside climatic changes, unplanned economic development, significant population pressure, land use change, upstream water withdrawal and urbanization directly affect water resources. Thus, climatic and non-climatic factors are responsible for changes in supply and demand of water resources, affecting the quantity and quality of water, which in turn has an impact on the society, the economy and the environment of the country.

\subsection{Design of the Feasibility Study}

For the practical implementation of the generalized framework and its refinement at LBRB context, the feasibility study was carried out involving key stakeholders in Bangladesh. With the involvement of the same stakeholders, a complete description of the proposed framework (i.e., description of each step) was also provided that could represent the core problems of water resources in the LBRB.

Table 1. Categorization of involved experts.

\begin{tabular}{|c|c|}
\hline Categorization of participants in terms of their current activities & Number \\
\hline $\begin{array}{l}\text { University professors who are also responsible for water resources planning for the } \\
\text { government of Bangladesh }\end{array}$ & 3 \\
\hline $\begin{array}{l}\text { Representative from the government organizations who are dealing with large scale water } \\
\text { projects }\end{array}$ & 3 \\
\hline $\begin{array}{l}\text { Representative from the government organizations who are dealing with small scale water } \\
\text { projects }\end{array}$ & 4 \\
\hline NGO representatives who are responsible for water planning and management & 7 \\
\hline $\begin{array}{l}\text { University teachers (Lecturer \& Asst. Professor) with research interest in water } \\
\text { management }\end{array}$ & 5 \\
\hline $\mathrm{PhD}$ researchers with research topic related to water management in Bangladesh & 5 \\
\hline Representative from local government & 3 \\
\hline
\end{tabular}

In order to identify the key stakeholders in the LBRB, organizations which play an important role in water management were selected. The lists of such organizations can be found in the Bangladesh Water Sector Review developed by the Asian Development Bank [64]. These organizations are the National Water Resources Council (NWRC), Water Resources Planning Organizations (WARPO), the Bangladesh Water Development Board (BWDB), the Local Government Engineering Department (LGED), several Non Governmental Organizations, several universities and research institutes, and water management associations (WMAs). Key personnel of these organizations were involved in the evaluation of the framework and also in the identification of elements of each of the defined components/steps that can represent the water resources problem of the LBRB. For the evaluation, a workshop was arranged and the framework was presented to 20 participants. A structured questionnaire (Annex A) was also provided for feedback. In addition to this, personal interviews were carried out with 10 relevant decision makers who were not able to attend the workshop. Therefore, a 
total of 30 experts were involved in the evaluation. The functions or current activities of these 30 participants are presented in Table 1 . The interviews were carried out with the same questionnaire (Annex, published as online supplementary material) used during the workshop and which incorporated aspects covering the evaluation of the proposed framework as a whole, the usefulness of the framework for water resources decision making, and the extent of the important steps that are incorporated in the proposed framework. Other aspects covered by the questionnaire were: the main concerns of Bangladesh and whether these concerns can be addressed by the generalized framework; steps of the framework which should be added/removed/refined; and questions related to the main weaknesses and strengths of the framework.

\subsection{Experts' Judgement on Proposed Framework}

With the involvement of key stakeholders in Bangladesh, we could carry out an analysis of the feasibility of practical implementation of the proposed framework. Stakeholders could evaluate the framework as 'excellent', 'very good', 'good', 'fair', 'poor', 'very poor'. However, in the evaluation, 21 participants out of $30(70 \%)$ considered the overall framework to be 'excellent', $20 \%$ considered it to be 'very good' and 10\% considered it to be 'good'. In evaluating the usefulness of the framework for water resources decision making in the LBRB, about $17 \%$ of the experts considered it to be 'excellent', 40\% considered it to be 'very good', 33\% considered it to be 'good' and $10 \%$ considered it to be 'fair'. Those who considered the usefulness of the framework to be 'good' and 'fair' had several concerns. First, according to their opinion, the current socio-economic settings and institutional and legislative context of Bangladesh may not allow to involve stakeholders to participate in all the steps of the decision making process. This is because people's participation is still very weak in current water management practices. For implementing participatory process, there is a great challenge of developing local capacities for water management which may still require improved adaptive management techniques through better education. Therefore, participants thought that it is not necessary to involve stakeholders in several steps, i.e., defining the scale and selecting the vulnerability model. Second, they argue that less emphasis is given on operation and maintenance as well as monitoring and evaluation, although it is mentioned in the framework. WARPO [65] also identified inefficient operation and maintenance as the prime causes of the malfunctioning of projects and usually post-evaluation of these projects with respect to their performance and impacts has not been carried out. In evaluating how important steps are incorporated in the framework, about 33\% of total participants considered the framework to be 'excellent', whereas, $44 \%$ considered it to be 'very good' and $23 \%$ to be 'good'.

According to the experts, the main concerns in terms of vulnerability assessment of the water resources system of the LBRB are water shortages during the dry season, flooding during the wet season, river bank erosion, institutional challenges, as well as other factors. Main institutional challenges are the lack of coordination among different agencies and sectors which may have resulted in various water related problems. However, $47 \%$ of the experts thought that all of these concerns could be addressed by this generic framework and 53\% of the experts thought that most of these concerns could be addressed in the proposed framework. 
The proposed generalized framework was considered to have as its main strengths the consideration of present but also future vulnerability, the participatory approach to decision making, uncertainty assessment and its communication among the stakeholders and the adaptability of the framework to any vulnerability concerns related to water resources. According to experts' opinions, the main weaknesses of the framework lie in the incorporation of stakeholders in all the steps which could be challenging, lack of coordination among agencies and sectors, monitoring and evaluation with the involvement of key stakeholders and government strategies of upstream countries which were not reflected in the framework. Considering all these issues, a revised framework was prepared which is described below.

\subsection{Results of the Feasibility Study and Revised Framework for LBRB}

Based on evaluation of collected information and the suggestions provided by the local experts, our proposed generalized framework was adapted and filled with preliminary results. In the revised framework, stakeholder involvement was considered in major steps instead of all steps, as this issue was one of the major concerns for the local experts. Following the feasibility study, also other agencies were to be selected. The results are placed in Figure $4 \mathrm{a}$. In the framework, the step 'monitoring and evaluation' was considered in the participatory way involving stakeholders (Figure 4n). Government strategies of upstream countries were considered in the step 'Define scenario' (Figure 4h). With the involvement of the same stakeholders we also identified components of each step that could provide a complete description of the proposed framework in the LBRB context which is schematized in Figure 4.

Key stakeholder identification is one of the main steps in the framework on which coordinated planning and development depends. Lack of coordination among key sectors may lead to complex problems. For example, uncoordinated planning and development between transportation and water sectors in the past led to a complex road network, restricted drainage, increased water logging and damming of seasonal streams [66]. Therefore, beside water management authorities identified as described in Section 4.2, key stakeholders from few other agencies were added which includes Bangladesh Agriculture Research Council (BARC), Bangladesh Rice Research Institute (BRRI), Bangladesh Inland Water Transport Authority (BIWTA), Bangladesh Fisheries Research Institute (BFRI). With the involvement of these stakeholders (see Figure 4a), the social-ecological system of the LBRB should be characterized. The LBRB is characterized as the floodplain with transboundary river where population pressure is high and the main economic activity is agriculture (Figure 4b). Dry season water shortages, flooding during the rainy season, and the river bank erosion are the main concerns with poor water management practices (Figure 4c). The region is also dominated by South-Asian monsoons which are responsible for the high variability in the temporal distribution of water, which creates two extremes: a water abundance regime with an excess of water leading to floods during the rainy season and a scarcity regime with no rainfall during the dry season [66]. The impact of climate change is expected to be high in monsoon dominated regions. 
Figure 4. Vulnerability assessment of water resources system: revision of the proposed generalized framework for implementation in the LBRB.

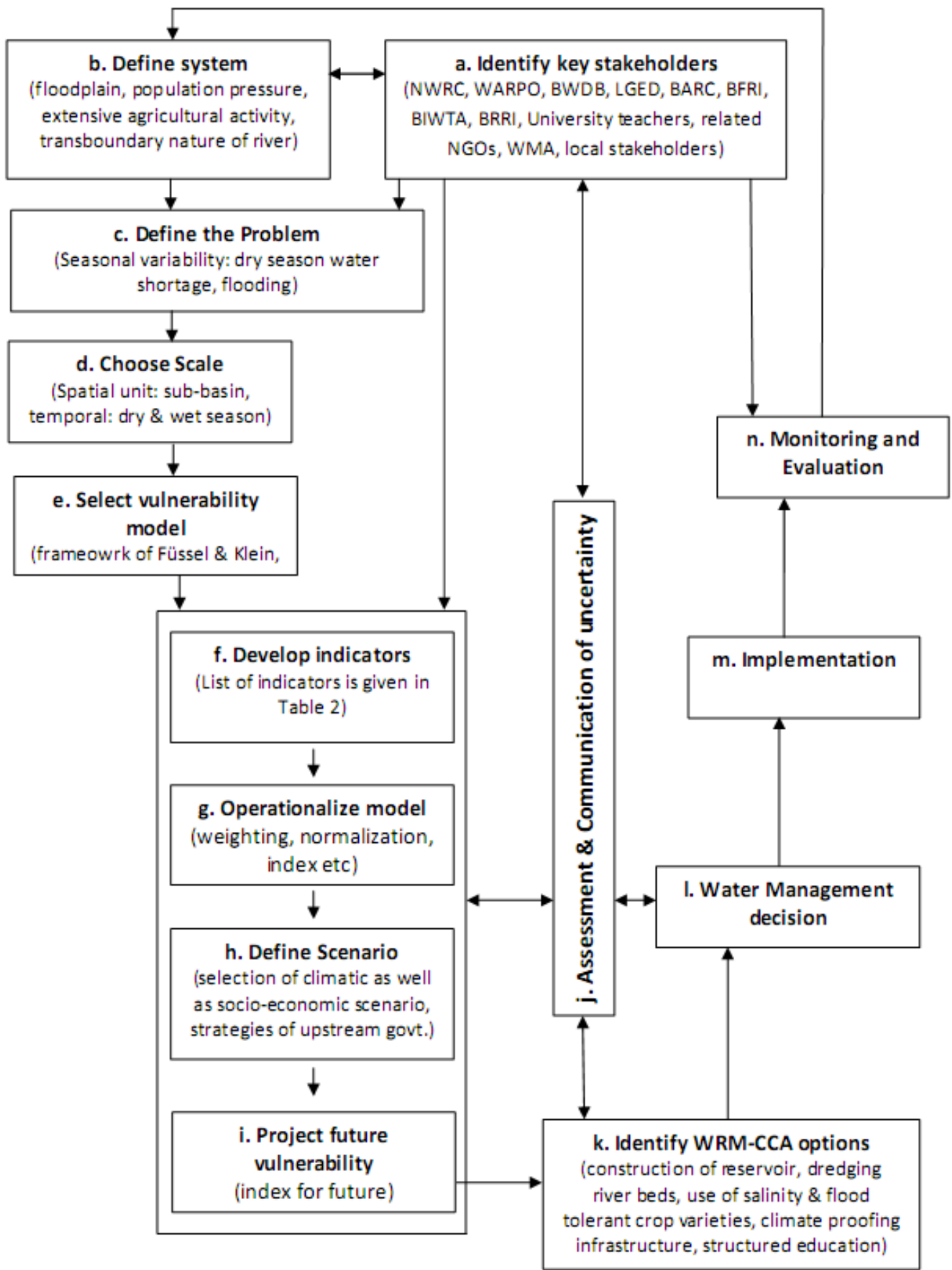

Based on the defined system, spatial and temporal units of analysis need to be selected (Figure 4d). The Brahmaputra crosses several countries and there is no integrated trans-boundary river basin planning approach. The sub-basin of the lower-Brahmaputra that is included in the geographical boundary of Bangladesh is considered as the spatial unit (the shaded white area of geographical Boundary of Bangladesh shown in Figure 5). Although, the lower part of the basin is considered as 
spatial unit, dealing with such trans-boundary river basin cross-scale considerations also need to be accounted for, including policies in riparian countries. In the case of temporal scales, we consider the scale of analysis as the dry (September-March) and the wet season (April-August). This is because, in the context of the LBRB, water flows are highly variable in the dry and wet season. Assessments of annual flows do not incorporate this variation and its associated impacts. A seasonal assessment is therefore to be considered for the analysis in the LBRB context. Given the purposes, study periods can be identified. Long term climate policies are now dealing with the assessment up to 2100 . However, in vulnerability assessment, it is difficult to consider long time spans because we cannot easily predict the future of social sub-systems. We can only make projections for several years depending on institutional strategies. In the context of the LBRB, it is recommended that projections be made for the next 40 years-until 2050. This is because in Bangladesh long term investments in water-related projects are based on this duration and institutional policies are also developed considering this timeframe [67].

Figure 5. Overview of the Brahmaputra river basin (red polygon), the Brahmaputra river (blue line), the outlines of the lower Brahmaputra river basin (shaded white).

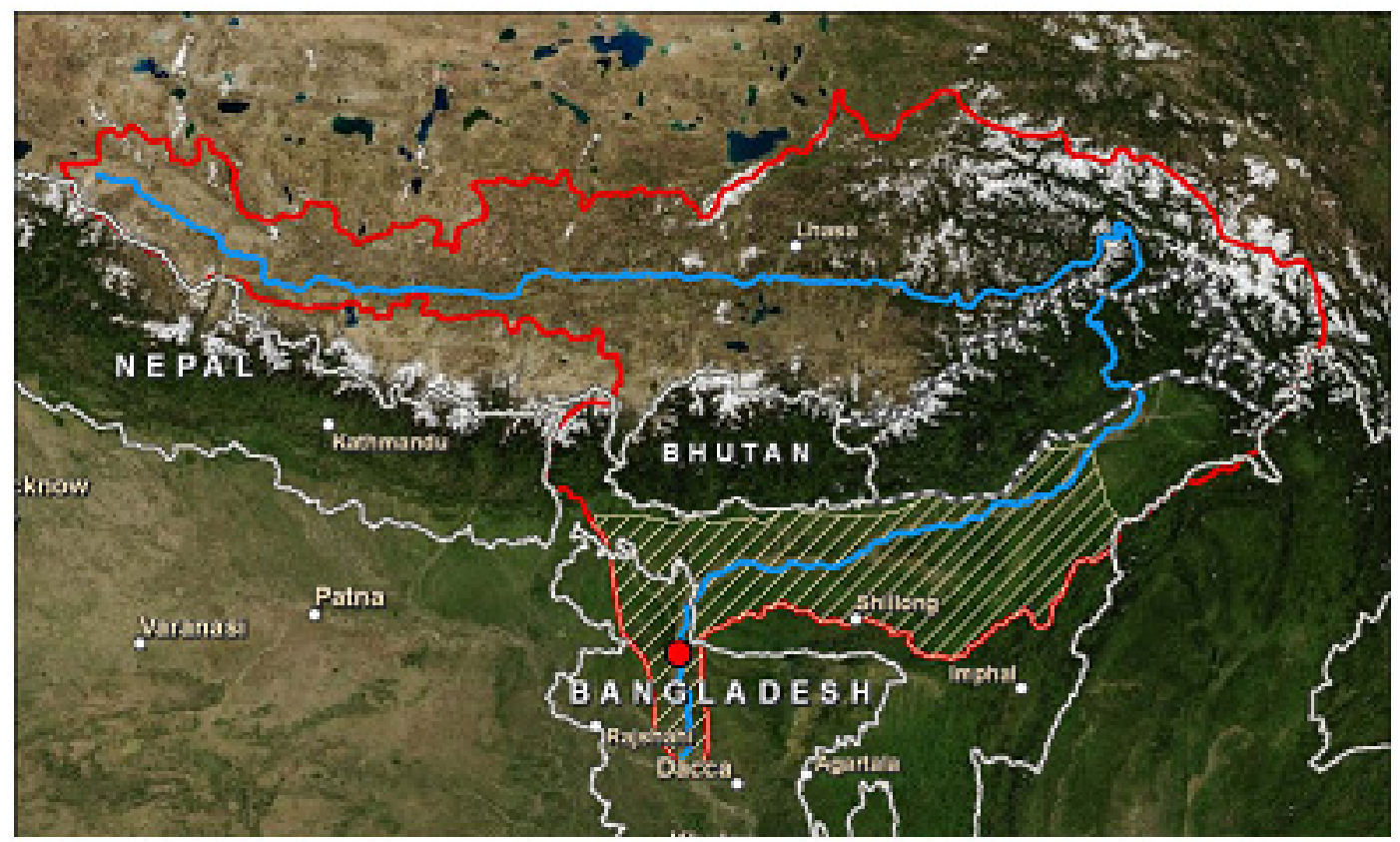

Given the purpose of vulnerability assessment in the LBRB as climate change adaptation, we propose to refer to the modified adaptation policy assessment model for vulnerability assessment provided by [12], which is now applied other ongoing studies by the authors. In this model, vulnerability is decomposed as the component of exposure, sensitivity, resilience and coping capacity. In this case the most representative indicators that can address the problem were selected for each component of vulnerability with the involvement of key stakeholders. The list of indicators is given in Table 2. With the involvement of stakeholders, indicators need to be prioritized through weighting. Data normalization is also required (Figure $4 \mathrm{~g}$ ). For assessing future vulnerability, climatic as well as different socio-economic scenarios should be selected. Uncertainties in climate change predictions need to be reduced through reliable methods of downscaling from Global Circulation Models and 
hydrologic models. In this case, multi-model ensemble analysis can play an important role. For assessing future river flow scenario of LBRB, Gain et al. [59] applied such approaches which can be incorporated in this study (in Figure 6). Government strategies of upstream countries need to be considered for assessing future vulnerability (Figure 4h). This is often quite complex and information between riparian countries can be difficult. After assessing present and future vulnerability, adaptation options need to be selected. During the workshop, involved stakeholders suggested building a reservoir as an adaptation strategy in Bangladesh that can store flood water for solving the dry season water shortage problem. They also suggested other adaptation measures like, dredging of river beds, salinity and flood resilient crop varieties, guidelines on climate proofing of infrastructure, structured education among local people (Figure 4k).

Table 2. Indicators of vulnerability components.

\begin{tabular}{|c|c|c|c|}
\hline $\begin{array}{c}\text { Main } \\
\text { Components }\end{array}$ & $\begin{array}{c}\text { Sub- } \\
\text { components }\end{array}$ & Acronym & Definition and selected indicator \\
\hline Exposure & $\begin{array}{c}\text { Water } \\
\text { availability }\end{array}$ & WA & $\begin{array}{l}\text { Future available water was calculated through assessing } \\
\text { future riverflow of lower Brahmaputra (at Bahadurabad } \\
\text { station) under different climate scenario (A1B \& A2). } \\
\text { Indicator: Riverflow of Brahmaputra at Bahadurabad station } \\
\left(\mathrm{m}^{3} / \mathrm{s}\right) \text {; source: [59]. }\end{array}$ \\
\hline \multirow{3}{*}{ Sensitivity } & Water Demand & WD & $\begin{array}{l}\text { Agricultural, domestic, industrial and in stream water demand } \\
\text { increase the sensitivity for the study area. Indicator: Total } \\
\text { water demand, which is the aggregation of agricultural, } \\
\text { domestic, industrial and instream water demand }\left(\mathrm{m}^{3} / \mathrm{s}\right) \text {; } \\
\text { source: [68]. }\end{array}$ \\
\hline & $\begin{array}{l}\text { Infrastructure } \\
\text { pressures at } \\
\text { Upstream }\end{array}$ & IP & $\begin{array}{l}\text { The sensitivity induced by alterations of the river flow at } \\
\text { upstream deriving from barrages, dams, etc. which may } \\
\text { increase the sensitivity. Indicator: Hydroelectrical installed } \\
\text { capacity (MW); source: own elaborations on data from the } \\
\text { development plans of the Central Electrical Authority of } \\
\text { India (http://www.cea.nic.in/) }\end{array}$ \\
\hline & $\begin{array}{c}\text { Forest Cover at } \\
\text { upstream }\end{array}$ & $\mathrm{FC}$ & $\begin{array}{l}\text { One of the most important strategies for controlling runoff } \\
\text { and erosion risks, thus limiting the probability of flood events } \\
\text { downstream. Indicator: Area forest cover at north-east India } \\
\left(\mathrm{km}^{2}\right) \text {; source: [69]. }\end{array}$ \\
\hline Resilience & $\begin{array}{l}\text { Agricultural } \\
\text { production }\end{array}$ & AP & $\begin{array}{l}\text { An activity that contributes to the maintenance of land with } \\
\text { positive potential for limiting the impacts of climate change. } \\
\text { Indicator: amount of rice production (ton), a proxy of } \\
\text { agricultural production; source: BARC. }\end{array}$ \\
\hline \multirow{2}{*}{$\begin{array}{l}\text { Coping } \\
\text { capacity }\end{array}$} & $\begin{array}{c}\text { Water } \\
\text { Governance }\end{array}$ & WG & $\begin{array}{l}\text { The status of water governance can determine the capacity } \\
\text { for the management of various problems of water resources. } \\
\text { Indicator: perceived trend of composite water governance } \\
\text { (numeric value between } 0 \text { to } 1 \text { ); Source: [70] }\end{array}$ \\
\hline & Poverty & $\mathrm{P}$ & $\begin{array}{l}\text { A second index of the economic wealth of the population, } \\
\text { here derived from the projections of the indicator "incidence } \\
\text { of poverty"; source: [71]. }\end{array}$ \\
\hline
\end{tabular}


Figure 6. Multi-model ensemble analysis of stream flow for different seasons and for different time slices.

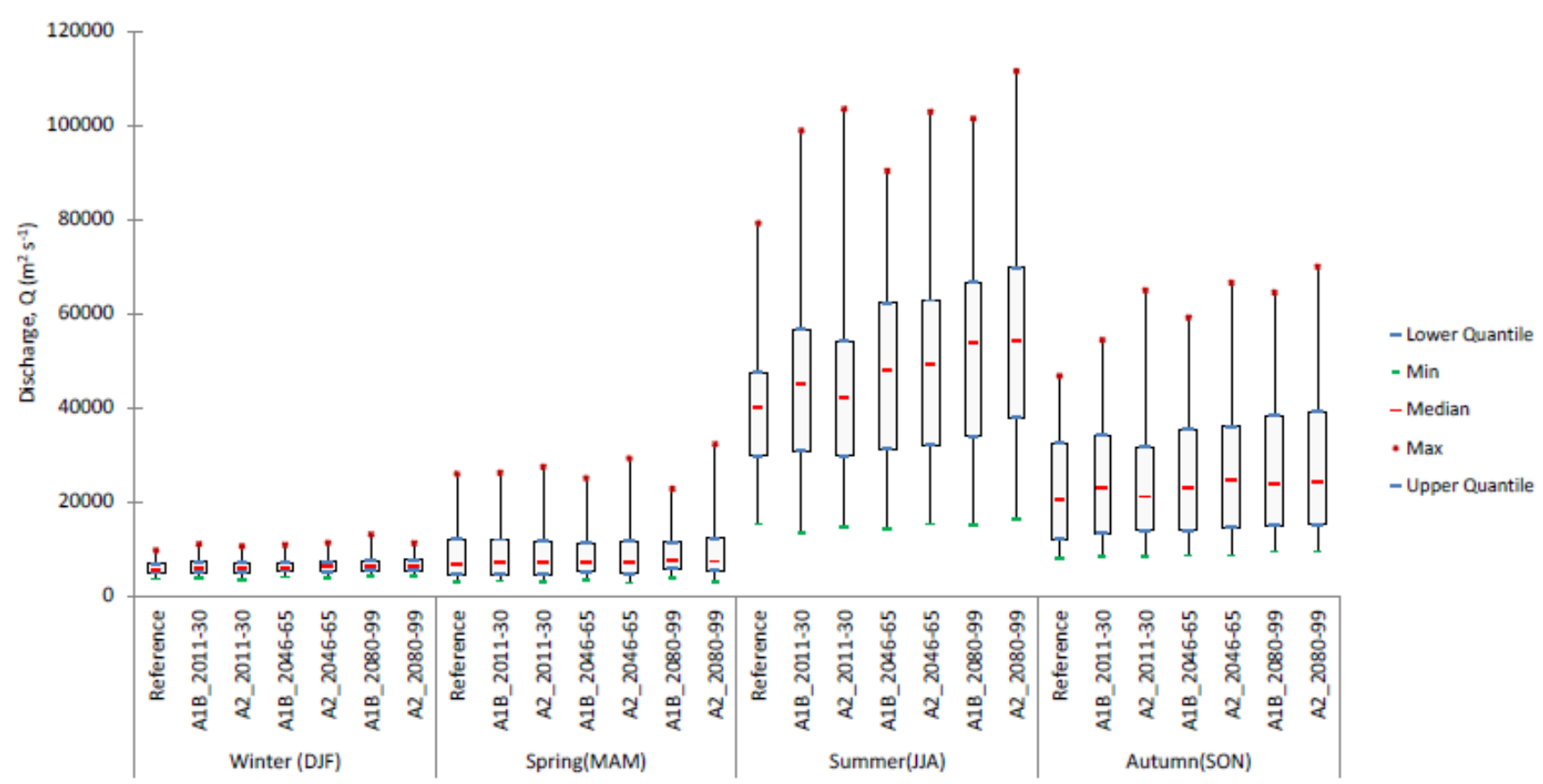

After selection of the appropriate adaptation options, water resources decision making should be implemented in a participatory way through improved monitoring and evaluation which may require integrating policies and updating existing national plans (Figure 4l-n). Various existing regulatory frameworks can be used or have to be further developed to implement decisions. In Bangladesh, the National Water Policy was already formulated in 1999 by the National Water Resources Council (NWRC), which plays a central role in water resources decision making. Besides the NWRC, the Water Resources Planning Organization (WARPO), the Bangladesh Water Development Board (BWDB) and the Local Government Engineering Department (LGED) are the principal bodies for water resources planning and decision making. With the collaboration of these organizations, existing regulatory frameworks can be used to implement the water resources decision and if require, they can also be further developed.

\section{Conclusions}

In this study, the concepts of vulnerability assessment for water resources systems was reviewed, with the aim of facilitating the work of those who are active in the field of water management in developing countries by moving towards operational solutions. We identified several conceptual gaps which were: (i) consideration of forward looking aspects (or future aspects) of vulnerability, (ii) seasonal level assessment reflecting both water abundance and scarcity regimes, (iii) a move towards dynamic assessments based upon the concept of social-ecological system, and participatory modeling.

In order to suggest a means to overcome these gaps, we developed a generalized methodological framework for vulnerability assessment and support the identification of preferable adaptation measures. A feasibility study of the proposed framework was carried out in the LBRB. Reflecting the feedback of local experts, some components of the framework were revised and all of them were 
defined in terms of specific solutions and contents in view of a possible future implementation in the specific context of the LBRB.

The proposed framework (in its revised version) organizes the various steps of vulnerability assessment in a transparent way that allows identifying the needs of methods, tools and data. The results of the feasibility study in Bangladesh showed the current main constraints which include: (i) weaknesses in local capacities for water management, (ii) lack of institutional coordination, and (iii) inefficient monitoring and evaluation. However, the feasibility study can benefit water managers in other areas having similar characteristics and problems (e.g., consideration of seasonal variability of water regimes in terms of both floods and droughts; up-stream-down-stream relationships, etc.).

Vulnerability assessment in this way may also play a significant role in identifying planned adaptation measures. In the water resources system, climate change adaptation should be framed within existing policies and other regulatory mechanisms and that may require further developments to facilitate mainstreaming. Further research is needed to identify main constraints limiting the potential for vulnerability assessments and climate change adaptation to be implemented into operational water resources management and planning. Such constraints could differ in nature and, in particular, could be related to institutional capacities and the efficient management of collaborative and participatory approaches. Water managers of any river basin or researchers in this field can follow these guidelines in order to assess vulnerability of water resources.

\section{Acknowledgments}

Part of this research was conducted at $\mathrm{Ca}$ ' Foscari University of Venice and at the United Nations University-Institute for Environment and Human Security (UNU-EHS).

\section{References and Notes}

1. Millennium Ecosystem Assessment. Ecosystem and Human Wellbeing: Current State and Trends; Island Press: Washington, DC, USA, 2005.

2. UN-Water. Key Messages on Climate Change and Water Prepared for COP-15; UN-Water: New York, NY, USA. Available online: http://www.unwater.org/downloads/UNWclimatechange_EN.pdf (accessed on 9 February 2012).

3. Bates, B.C.; Kundzewicz, Z.W.; Wu, S.; Palutikof, J.P. Climate Change and Water; Technical Paper for Intergovernmental Panel on Climate Change: Geneva, Switzerland, 2008.

4. Chalecki, E.L.; Gleick, P.H. A framework of ordered climate effects on water resources: A comprehensive bibliography. J. Am. Water Resour. As. 1999, 35, 1657-1665.

5. Kundzewicz, Z.W.; Mata, L.J.; Arnell, N.W.; Döll, P.; Kabat, P.; Jiménez, B.; Miller, K.A.; Oki, T.; Sen, Z.; Shiklomanov, I.A. Freshwater resources and their management. In Climate Change 2007: Impacts, Adaptation and Vulnerability. Contribution of Working Group II to the Fourth Assessment Report of the Intergovernmental Panel on Climate Change; Parry, M.L., Canziani, O.F., Palutikof, J.P., van der Linden, P.J., Hanson, C.E., Eds.; Cambridge University Press: Cambridge, UK, 2007; pp. 173-210. 
6. Thywissen, K. Components of Risk: A Comparative Glossary; Studies of the University: Research, Counsel, Education (SOURCE) Publication Series No 2; United Nations UniversityInstitute for Environment and Human Security (UNU-EHS): Bonn, Germany, 2006.

7. Cutter, S.L. Vulnerability to environmental hazards. Prog. Hum. Geog. 1996, 20, 529-539.

8. Jones, R.N. An environmental risk assessment/management framework for climate change impact assessments. Nat. Hazards 2001, 23, 197-230.

9. Brooks, N.; Adger, W.N.; Kelly, P.M. The determinants of vulnerability and adaptive capacity at the national level and the implications for adaptation. Global Environ. Change 2005, 15, 151-163.

10. Turner, B.L.; Kasperson, R.E.; Matsone, P.A.; McCarthy, J.J.; Corell, R.W.; Christensen, L.; Eckley, L.; Kasperson, J.X.; Luerse, A; Martello, M.L.; et al. A framework for vulnerability analysis in sustainability science. Proc. Natl. Acad. Sci. USA 2003, 100, 8074-8079.

11. Luers, A.L. The surface of vulnerability: An analytical framework for examining environmental change. Global Environ. Change 2005, 15, 214-223.

12. Füssel, H.M.; Klein, R.J.T. Climate change vulnerability assessments: An evolution of conceptual thinking. Climatic Change 2006, 75, 301-329.

13. Füssel, H.M. Vulnerability: A generally applicable conceptual framework for climate change research. Global Environ. Change 2007, 17, 155-167.

14. Moss, R.H.; Brenkert, A.L.; Malone, E.L. Vulnerability to Climate Change: A Quantitative Approach; Technical Report PNNL-SA-33642; Pacific Northwest National Laboratory: Richland, WA, USA, 2001.

15. Patt, A.G.; Schroter, D.; de la Vega-Leinert, A.C.; Klein, R.J.T. Vulnerability research and assessment to support adaptation and mitigation: Common themes from the diversity of approaches. In Environmental Vulnerability Assessment; Patt, A.G., Schroter, D., de la Vega-Leinert, A.C., Klein, R.J.T., Eds.; Earthscan: London, UK, 2008.

16. Hinkel, J. Indicators of vulnerability and adaptive capacity-Towards a clarification of the science-policy interface. Global Environ. Change 2011, 21, 198-208.

17. Simonovic, S.P. Water Resources Management: A System View. Available online: http://www.siwi.org/documents/Resources/Water_Front_Articles/2009/WRMASystemsView.pdf (accessed on 9 February 2012).

18. Hyde, K.M.; Maier, H.R.; Colby, C.B. Reliability-based approach to multicriteria decision analysis for water resources. J. Water Res. Pl-ASCE 2004, 130, 429-438.

19. Tessendorff, H. The Dublin statement on water and sustainable development. Presented at International Conference on Water and Environment, Dublin, Ireland, 29-31 December 1992. Available online: http://www.inpim.org/files/Documents/DublinStatmt.pdf (accessed on 8 February 2012).

20. Vörösmarty, C.J.; Green, P.; Salisbury, J.; Lammers, R.B. Global water resources: Vulnerability from climate change and population growth. Science 2000, 289, 284-288.

21. Babel, M.S.; Wahid, S.M. Freshwater Under Threat: South Asia-Vulnerability Assessment of Freshwater Resources to Environmental Change; United Nations Environment Programme: Nairobi, Kenya, 2009.

22. Hamouda, M.A.; Nour El-Din, M.M.; Moursy, F.I. Vulnerability assessment of water resources system in the Eastern Nile Basin. Water Resour. Manag. 2009, 23, 2697-2725. 
23. Hurd, B.; Leary, N.; Jones, R.; Smith, J. Relative regional vulnerability of water resources to climate change. J. Am. Water Resour. Assoc. 1999, 35, 1399-1409.

24. Sullivan, C.A. Quantifying water vulnerability: A multi-dimensional approach. Stoch. Env. Res. Risk Assess. 2011, 25, 627-640.

25. Pandey, V.P.; Babel, M.S.; Kazama, F. Analysis of a Nepalese water resources system: Stress, adaptive capacity and vulnerability. Water Sci. Technol. 2009, 9, 213-222.

26. Gober, P.; Kirkwood, C.W. Vulnerability assessment of climate-induced water shortage in Phoenix. Proc. Natl. Acad. Sci. USA 2010, 107, 21295-21299.

27. Pandey, V.P.; Babel, M.S.; Shrestha, S.; Kazama, F. Vulnerability of freshwater resources in large and medium Nepalese river basins to environmental change. Water Sci. Technol. 2010, 61, $1525-1534$.

28. Pandey, V.P.; Babel, M.S.; Shrestha, S.; Kazama, F. A framework to assess adaptive capacity of the water resources system in Nepalese river basins. Ecol. Indic. 2011, 11, 480-488.

29. Balica, S.F.; Douben, N.; Wright, N.G. Flood vulnerability indices at varying spatial scales. Water Sci. Technol. 2009, 60, 2571-2580.

30. Birkmann, J. Measuring vulnerability to promote disaster-resilient societies: Conceptual frameworks and definitions. In Measuring Vulnerability to Natural Hazards-Towards Disaster Resilient Societies; Birkmann. J., Ed.; United Nations University Press: Tokyo, Japan, 2006; pp. 9-54.

31. Adger, W.N. Vulnerability. Global Environ. Change 2006, 16, 268-281.

32. Gallopín, G.C. Linking between vulnerability, resilience and adaptive capacity. Global Environ. Change 2006, 16, 293-303.

33. Wisner, B.; Blaikie, P.; Cannon, T.; Davis, I. At Risk: Natural Hazards, People's Vulnerability, and Disasters, 2nd ed.; Routledge: London, UK, 2004.

34. Bogardi, J.; Birkmann, J. Vulnerability assessment: The first step towards sustainable risk reduction. In Disaster and Society_From Hazard Assessment to Risk Reduction; Malzahn, D., Plapp, T., Eds.; Logos Verlag Berlin: Berlin, Germany, 2004; pp. 75-82.

35. Cardona, O.D. Estimación Holística del Riesgo Sísmico Utilizando Sistemas Dinámicos Complejos; Ph.D. Dissertation. Technical University of Catalonia, Barcelona, Spain, September 2001.

36. Bohle, H.G. Vulnerability and criticality: Perspective from social geography. In IHDP Update 2/2001; Dyck, E., Ed.; International Human Dimensions Programme on Global Environmental Change: Bonn, Germany, 2001; pp. 3-5.

37. Eakin, H.; Tompkins, E.L.; Nelson, D.R.; Anderies, J.M. Hidden costs and disparate uncertainties: Trade-offs in approaches to climate policy. In Adapting to Climate Change: Thresholds, Values, Governance; Adger, W.N., Lorenzoni, I., O’Brien, K.L., Eds.; Cambridge University Press: Cambridge, UK, 2009; pp. 212-226

38. Torry, W.I.; Anderson, W.A.; Bain, D.; Otway, H.J.; Souza, F.D.; Keefe, P.O. Anthropological studies in hazardous environments: Past trends and new horizons. Curr. Anthropol. 1979, 20, 515-540.

39 Torry, W.I. Bureaucracy, community, and natural disasters. Hum. Organ. 1978, 37, 302-308.

40 Mercer, J. Disaster risk reduction or climate change adaptation: Are we reinventing the wheel? J. Int. Dev. 2010, 22, 247-264. 
41. Thomalla, F.; Downing, T.; Siegfried, E.S.; Han, G.; Rockström, J. Reducing hazard vulnerability: Towards a common approach between disaster risk reduction and climate adaptation. Disasters 2006, 30, 39-48.

42. Renaud, F.; Perez, R. Climate change vulnerability and adaptation assessments. Sustain. Sci. 2010, 5, 155-157.

43. UN/ISDR. Living With Risk-A Global Review of Disaster Reduction Initiatives; UN/ISDR: Geneva, Switzerland, 2004.

44. IPCC. Summary for the policy makers. In Climate Change 2007: Impacts, Adaptation and Vulnerability. Contribution of Working Group II to the Fourth Assessment Report of the Intergovernmental Panel on Climate Change; Parry, M.L., Canziani, O.F., Palutikof, J.P., van der Linden, P.J., Hanson, C.E., Eds.; Cambridge University Press: Cambridge, UK, 2007; pp. 7-22.

45. IPCC. Annex B: Glossary of terms. In Climate Change 2001: Impacts, Adaptation and Vulnerability; McCarthy, J.J., Canziani, O.F., Leary, N.A., Dokken, D.J., White, K.S., Eds.; Cambridge University Press: Cambridge, UK, 2001; p. 995.

46. UN-Water. Status Report on Integrated Water Resources Management and Water Efficiency Plans for the 16th session of the Commission on Sustainable Development; UN-Water: New York, NY, USA, 2008.

47. GWP-TAC. Integrated Water Resources Management; Background Paper No. 4; Global Water Partnership/Technical Advisory Committee: Stockholm, Sweden, 2000.

48. UNESCO. Water in a Changing World; The United Nations World Water Development Report 3, World Water Assessment Programme (WWAP); UNESCO Publishing: Paris, France; Earthscan: London, UK, 2009.

49. Oki, T.; Agata, Y.; Kanae, S.; Saruhashi, T.; Yang, D.; Musiake, K.; Global assessment of current water resources using total runoff integrating pathways. Hydrolog. Sci. J. 2001, 46, 983-996.

50. Oki, T.; Sato, M.; Kawamura, A.; Miyake, M.; Kanae, S.; Musiake, K. Virtual water trade to Japan and in the world. In Virtual Water Trade: Proceedings of the International Expert Meeting on Virtual Water Trade, Research Report Series No. 12; Hoekstra, A.Y., Ed.; The UNESCO-IHE Institute for Water Education: Delft, The Netherlands, 2003.

51. Alcamo, J.; Döll, P.; Henrichs, T.; Kaspar, F.; Lehner, B.; Rosch, T.; Siebert, S. Global estimation of water withdrawals and availability under current and "business as usual" conditions. Hydrol. Sci. J. 2003, 48, 339-348.

52. Oki, T.; Kanae, S. Global hydrological cycles and world water resources. Science 2006, 313, 1068-1072.

53. Islam, S.; Oki, T.; Kanae, S.; Hanasaki, N.; Agata, Y.; Yoshimura, K. A grid-based assessment of global water scarcity including virtual water trading. Water Resour. Manag. 2007, 21, 19-33.

54. Huang, Y.; Cai, M. Methodologies Guideline for Vulnerability Assessment of Freshwater Resources to Environmental Change; United Nations Environment Programme: Nairobi, Kenya, 2009.

55. Cash, D.W.; Adger, W.N.; Berkes, F.; Garden, P.; Lebel, L.; Olsson, P.; Pritchard, L.; Young, O. Scale and cross-scale dynamics: Governance and information in a multilevel world. Ecol. Soc. 2006, 11, article 8. Available online: http://www.ecologyandsociety.org/vol11/iss2/art8/ (accessed on 29 Mar 2012). 
56. Damm, M. Mapping Social-ecological Vulnerability to Flooding-A Sub-national Approach for Germany; Graduate Research Series Volume 3; United Nations University-Institute for Environment and Human Security (UNU-EHS): Bonn, Germany, 2010.

57. Adger, W.N.; Brooks, N.; Bentham, G.; Agnew, M.; Eriksen, S. New Indicators of Vulnerability and Adaptive Capacity; Tyndall Centre for Climate Change Research Report 7; Tyndall Centre: Norwich, UK, 2004.

58. Saaty, T.L. The Analytical Hierarchy Process, Planning, Priority Setting, Resource Allocation; McGraw-Hill: New Work, NY, USA, 1980.

59. Beinat, E. Value Functions for Environmental Management; Kluwer Academic Publishers: Norwell, MA, USA, 1997.

60. Immerzeel, W. Historical trends and future predictions of climate variability in the Brahmaputra basin. Int. J. Climatol. 2008, 28, 243-254.

61. Gain, A.K.; Immerzeel, W.W.; Weiland, F.C.S.; Bierkens, M.F.P. Impact of climate change on the stream flow of lower Brahmaputra: Trends in high and low flows based on discharge-weighted ensemble modeling. Hydrol. Earth Syst. Sci. 2011, 15, 1537-1545.

62. Mirza, M.M.Q. Global warming and changes in the probability of occurrence of floods in Bangladesh and implications. Global Environ. Change 2002, 12, 127-138.

63. Warrick, R.A.; Bhuiya, A.H.; Mirza, M.Q. The greenhouse effect and climate change. In The Implications of Climate and Sea-Level Change for Bangladesh; Warrick, R.A., Ahmad, Q.K., Eds.; Kluwer Academic Publishers: Dordrecht, the Netherlands, 1996.

64. ADB. Bangladesh Water Sector Review: Water Sector Roadmap Bangladesh; Asian Development Bank: Manila, Philippine, 2003.

65. WARPO. Review of Planned and Actual O\&M of Water Sector Projects; Working Paper 8.05; Water Resources Planning Organization (WARPO): Dhaka, Bangladesh, 1999.

66. Gupta, A.D.; Babel, M.S.; Albert, X.; Mark, O. Water sector of Bangladesh in the context of integrated water resources management: A review. Int. J. Water Resour. D. 2005, 21, 385-398.

67. WARPO. National Water Management Plan: Summary; Water Resources Planning Organization (WARPO): Dhaka, Bangladesh, 2001.

68. Mondal, M.S.; Chowdhury, J.U.; Ferdous, M.R. Risk-based evaluation for meeting future water demand of the Brahmaputra floodplain within Bangladesh. Water Resour. Manag. 2010, 24, 835-852.

69. Bujarbarua, P.; Baruah, S. Vulnerability of fragile forest ecosystem of North East India in context with the global climate change: An ecological projection. 2009 IOP Conf. Ser. Earth Environ. Sci. 2009, 6, doi:10.1088/1755-1307/6/7/072016.

70. Gain, A.K.; Schwab, M. An assessment of water governance trends: The case of Bangladesh. Water Policy 2012, in press.

71. Titumir, R.A.M.; Rahman, K.M.M. Poverty and Inequality in Bangladesh; Unnayan Onneshan: Dhaka, Bangladesh, 2011.

(C) 2012 by the authors; licensee MDPI, Basel, Switzerland. This article is an open access article distributed under the terms and conditions of the Creative Commons Attribution license (http://creativecommons.org/licenses/by/3.0/). 